\title{
El Gontrol del Contexto Educativo en Colombia: aproximación inicial desde el Análisis discursivo
}

\author{
Martha Isabel Barrero Galindo \\ marthaisabel.barrero@usco.edu.co \\ Miguel Ángel Mahecha B. \\ miguelangel.mahecha@usco.edu.co \\ Grupo de investigación IPPE
}

E 1 análisis crítico del discurso es un tipo de investigación analítica sobre el discurso que estudia primariamente el modo en que el abuso del poder social, el dominio y la desigualdad son practicados, reproducidos, y ocasionalmente combatidos, por los textos y el habla en el contexto social y politico ${ }^{20}$. Se interesa especificamente en el estudio crítico de las cuestiones y problemas sociales, en la desigualdad social, la dominación y los fenómenos relacionados con ellas, en general y en la función que cumplen el discurso, el uso del lenguaje o la comunicación en tales fenómenos, en particular.

Las prácticas discursivas pueden tener efectos ideológicos de peso, es decir, pueden ayudar a producir y reproducir relaciones de poder desiguales entre las clases sociales, las mujeres y los hombres, las mayorías y las minorías culturales o étnicas, por medio de la manera como representan los objetos y sitúan a las personas. Ni la carga ideológica de los modos particulares de utilización del lenguaje, ni las relaciones de poder subyacentes suelen resultar evidentes a las personas. El análisis crítico del discurso se propone logar que estos aspectos opacos del discurso se vuelvan más transparentes ${ }^{21}$.

El discurso se analiza no solamente como un objeto "verbal" autónomo, sino también como una interacción situada, como una práctica social o como un tipo de comunicación que se da en una situación social, cultural, histórica o política inmersa en un marco temporal o espacial, las circunstancias especiales, los participantes, los papeles comunicativos y sociales que cumplen y las diversas actividades adicionales que se realizan al mismo tiempo 22 .

El análisis crítico del discurso indaga especificamente sobre las relaciones complejas que existen entre la estructura social y la estructura del discurso y las maneras en que

\footnotetext{
${ }^{20}$ VAN DIJK Teun A .El Arıálisis Critico del Discurso. En: Anthropos (Barcelona), 186, septiembre-octubre 1999, pp. 23-36.

${ }^{21}$ FAIRCLOUGH, Norman y WODAK, Ruth. Análisis Crítico del Discurso. En: El Discurso Como Interacción Social. Teun Van Dijk, Compilador. Editorial Gedisa. España, 2008. P. 368.

${ }^{22}$ VAN DIJK Teun A. Discurso y Poder. Editorial Gedisa. España, 2009. P. 23.
} 
pueden variar las estructuras del discurso de la estructura social. El abuso de poder sólo puede manifestarse en el uso del lenguaje si existe la posibilidad de variación o elección. Hay casos en los que las estructuras de dominación no sólo influyen en las opciones y variaciones del uso del lenguaje o el discurso, sino que lo hacen en todos los sistemas discursivos o semióticos, los géneros y otras prácticas sociales.

En nuestro caso, apelamos tanto a los desarrollos liderados por la escuela del holandés van Dijk pero mencionamos, por sus propuestas complementarias, la escuela francófona que va desde Pêcheux, pasando por Charaudeau hasta llegar a Moeschler \& Reboul ${ }^{23}$. Rápidamente mencionaremos algunas de las características más representativas de estos autores.

Los trabajos de Pêcheux han mostrado desde sus comienzos un interés muy marcado por la epistemología y a lo largo de su obra esta perspectiva marcará la singularidad de su propuesta. Basta con leer un artículo del año $1984^{24}$ en donde desarrolla elementos de análisis de la epistemología del discurso. Pêcheux acude a las nociones althuserianas para acercarse a las ciencias sociales. No obstante, no hay una reflexión muy clara sobre análisis del discurso; habría que esperar prácticamente el final de la década de los sesenta para leer dos contribuciones suyas ${ }^{25}$ cuya particularidad ¡claramente discursiva!- reside en el hecho de haber sido publicadas bajo el seudónimo de Thomas Herbert. En la primera contribución, publicada en 1966, él aplica los conceptos de Bachelard y de Althusser a las ciencias sociales, y especialmente a la psicología social. Concluye que estas ciencias no han sido constituidas como ciencias propiamente dichas ya que ellas no han construido su propio objeto teórico. En otras palabras, no han logrado lo que en términos bachelardianos se conoce como la ruptura epistemológica de la ideología. Estas ciencias no producen pues un saber científico sino que más bien reproducen la ideologia del sistema social. Siguiendo el mismo enfoque epistemológico de Bachelard, Canguilhem y Althusser, Pêcheux afirma que, para convertirse en verdaderas ciencias, las ciencias sociales deben sufrir una transformación teórica que comprende, tanto una redefinición de sus objetos y de sus instrumentos. Mientras que la práctica corriente de las 'ciencias sociales' consiste en cambiar un discurso (ideológico) por otro discurso (ideológico), las ciencias sociales deberán transformar este discurso - lo que en nuestro estudio hemos denominado 'tejido discursivo'en otra cosa diferente, expresable en términos de una nueva teoría. Así pues, el análisis del discurso se considera como un instrumento de una ciencia social que debe ser refundada teóricamente para poder constituirse, es decir, lograr legitimidad discursiva.

En 1968, Pêcheux propone en un segundo artículo su tesis principal: "toda ciencia es principalmente ciencia de la ideología de la cual, inevitablemente se desprende" (p. 74).Pêcheux será recordado por su modelo de 'análisis automático del discurso' (AAD) en donde propone, a grandes rasgos, desarrollar un instrumento susceptible de producir resultados experimentales (producidos por una práctica

\footnotetext{
${ }^{23}$ Véase en la bibliografia los documentos respectivos.

${ }^{24}$ Pêcheux, Michel. Sur les contextes épistémologiques de l'analyse de discours. In: Mots, octobre 1984, N9. pp. 7-17.

${ }^{25} 1966$ y 1968 HERBERT Thomas (1966) "Réflexions sur la situation théorique des sciences sociales et, spécialement, de la psychologie sociale " Cahiers pour l'analyse 2 : 174-203. - (1968) - "Remarques pour une théorie générale des idéologies ", Cahiers pour l'analyse 9 : 74-92.
} 
ligada obligatoriamente a una teoria) y no resultados intuitivos (basados en la experiencia personal). Con el fin de explicar el sentido del discurso, debe pues constituir un instrumento que tome los discursos (no su sentido) como entrada y que por contera provea como salida datos sobre sus sentidos.

El objetivo del AAD es proveerle al analista un manejo metafórico que de cuenta de la producción del sentido en condiciones de producción que poco a poco se habrán especificado.

Para el caso del modelo formulado por Charaudeau, su propuesta se recoge en lo que se puede denominar un análisis semiolingüístico del discurso: "Sémio- de semiosis, indica que la construcción del sentido y su configuración se llevan a cabo por medio de una relación entre forma y sentido (en diferentes sistemas semiológicos), bajo la responsabilidad de un sujeto de intencionalidad inscrito en un marco de acción y teniendo un proyecto de influencia social; lingüístico porque muestra que esta forma está compuesta en esencia por materia lingüistica -la de las lenguas- que, por el hecho de su doble articulación, de la particularidad combinatoria de sus unidades (sintagmático-paradigmático, en varios niveles: palabra, oración, texto), impone un procedimiento de semiotización del mundo diferente del de otros lenguajes." $(1995,98)^{26}$.

En esa misma dirección, Mœschler \& Reboul (2000), evidencian su preocupación por precisar el marco teórico del análisis del discurso y su objeto discurso. En otras palabras, defienden el 'tejido discursivo'; en sus palabras: "El modelo de interpretación de los discursos que hemos desarrollado se apoya en las nociones de intención informativa, intención comunicativa y teoría de la mente. Según nuestra opinión, el productor de un discurso dado tiene la intención comunicativa global que vale por el conjunto de su discurso y tiene, igualmente, una intención informativa global que, también, vale por el conjunto de su discurso. En consecuencia, la tarea del productor de un discurso es el de construir su discurso de tal forma que, a partir de la recuperación de las intenciones informativas locales sucesivas (es decir a partir de la recuperación de las intenciones informativas locales sucesivas, para cada enunciado), el interlocutor logra identificar la intención informativa global del hablante por el conjunto de su discurso." ${ }^{27}$.

Según Van Dijk ${ }^{28}$, los estudios del discurso podrán definirse más específicamente como críticos si no solamente se limitan a estudiar los problemas sociales o las formas de desigualdad por que estas sean materia interesante de estudio, sino que además lo hacen explícitamente con el objeto de contribuir a producir un cambio social especifico a favor de los grupos dominados. De igual manera, el autor expresa que es crítico en la medida en que satisfaga uno o varios de los siguientes criterios, en los cuales "dominación" significa "abuso del poder social por parte de un grupo social":

- Las relaciones de dominación se estudian primariamente desde la perspectiva del interés del grupo dominado y a favor de éste.

- Las experiencias de (los miembros de) los

\footnotetext{
${ }^{26}$ Charaudeau, P. " Une analyse sémiolinguistique du discours ". Langages 117, 96-111. 1995.

${ }^{27}$ Moschler, J., Reboul, A. " Pourquoi l'analyse du discours a-t-elle besoin d'une théorie de l'esprit?? " in Berthoud, A-C. \& Mondada, L. (éds) (2000): Modèles du discours en confrontation, Berne, Peter Lang, 185-203.

${ }^{28}$ VAN DIJK Teun A. Discurso y Poder. Editorial Gedisa. España, 2009. P. 26 - 27.
} 
grupos dominados se emplean además como prueba para evaluar el discurso dominante.

- El estudio puede mostrar que las acciones discursivas del grupo dominante son ilegitimas.

- Pueden formularse alternativas a los discursos dominantes que coinciden con los intereses de los grupos dominados.

\section{Relación entre Discurso y Poder}

El poder social es el control que ejerce un grupo sobre otros grupos y sus miembros. En este sentido, el control es el que se ejerce sobre las acciones de los otros. Pero si el control se ejerce además en beneficio de aquellos que lo poseen y en detrimento de los sujetos controlados, podemos hablar de abuso del poder. Las personas ya no son libres de hablar o de escribir cuando, donde, a quien, sobre qué o cómo quieren hacerlo, sino que están controladas, en parte o enteramente, por otros entes poderosos, tales como el Estado, la policía, los medios o una empresa comercial. Existen las restricciones sociales de leyes o de normas sobre lo que es apropiado y lo que no lo es. El control también se aplica a las mentes de los sujetos controlados, es decir a su conocimiento, a sus opiniones, sus actitudes y sus ideologias, asi como a otras representaciones personales y sociales. El control de las mentes es indirecto, y quienes controlan directamente el discurso pueden controlar indirectamente la mente de la gente y por supuesto controlar indirectamente la acción. Esta acción controlada puede ser a su vez discursiva, de tal modo que el discurso de los poderosos termine por influir, indirectamente, en otros discursos que lleven agua para el molino de quienes están en el poder ${ }^{29}$.

\section{Control del contexto}

El primer paso que se debe dar para controlar el discurso, es controlar el contexto. Las élites u organizaciones poderosas pueden decidir quiénes, cuándo y dónde y con qué objetivos participan de un determinado evento comunicativo. Se debe examinar por ende los modos en que quienes están en el poder regulan el acceso al discurso: medios de comunicación, quienes reproducen las noticias, organizan conferencias, tipos de comunicados de prensa, a quienes se entrevista y cita con frecuencia, etc.

Intuitivamente, el contexto parece implicar algún tipo de entorno o circunstancias para un suceso, acción o discurso. Algo que funciona como trasfondo, marco, ambiente, condiciones o consecuencias. En el estudio del discurso como acción e interacción, el contexto es crucial. La distinción principal entre el análisis abstracto del discurso y el análisis social del mismo es que el segundo se toma en cuenta el contexto... el discurso se produce, comprende y analiza en relación con las características del contexto. Por lo tanto, se interpreta que el análisis social del discurso define el texto y el habla como situados: describe el discurso como algo que ocurre o se realiza en una situación social ${ }^{30}$.

Sin embargo no todas las propiedades de una situación social son parte del contexto de un discurso. Los participantes humanos parecen ser elementos cruciales del contexto, y también lo

"VAN DIJK Teun A. Discurso y Poder. Editorial Gedisa. España, 2009. P. 29 - 30.

${ }^{30}$ VAN DIJK, Teun A. El Discurso como Interacción en la Sociedad. En: El Discurso Como Interacción Social. Teun Van Dijk, Compilador. Editorial Gedisa. España, 2008. P. 32. 
son actores verbales. Otras propiedades de los participantes son frecuentemente (pero no siempre) relevantes, tales como ser hombre o mujer, ser joven o viejo, o tener poder, autoridad o prestigio. Consideramos que estas propiedades son contextuales porque pueden influenciar la producción o interpretación de (las estructuras de) el texto y el hablar; por ejemplo pueden tener influencia en el uso de pronombres o verbos especiales, en la elección de temar o en el empleo de formas de cortesia. En síntesis podemos en forma provisional, definir el contexto como la estructura de aquellas propiedades de la situación social que son sistemáticamente (es decir, no casualmente) relevantes para el discurso.

Un ejemplo de Control del Contexto Educativo: La Instrucción Pública en la Regeneración 1886 $-1899$

Para este periodo, los lineamientos educativos estuvieron direccionados por el partido conservador, que se consolidó como grupo hegemónico una vez fue derrotado el partido liberal. Este periodo políticamente se caracterizó como el de la Regeneración, fue una etapa de la vida nacional y regional bastante convulsionada, donde la lucha por el poder y el establecimiento de una carta política que rigiera la vida de los ciudadanos colombianos era una prioridad; en estos momentos el general Rafael Núñez trazaba sus lineamientos que vendrian a materializarse con la Constitución de 1886.

Este fue precisamente el momento en que la nación se convirtió en una República unitaria; desapareciendo los estados federados para darle paso a los departamentos y su subdivisión en municipios; al fortalecimiento de los poderes del ejecutivo, a la ampliación del periodo presidencial a seis años, la consolidación de la alianza iglesia -Estado en el concordato del 87, el fortalecimiento del Banco Nacional y la creación de un ejército nacional profesional. Esta constitución buscó, a través de sus políticas legislativas, dar "un orden" para el pais a través de la legislación administrativa, pena, civil, comercial y minera, dando paso a la creación de organismos, instituciones y empresas que contribuyeran a consolidar el nuevo Estado; determinando de esta manera los derroteros sobre la concepción y organización de la Nación, además del papel que debería desempeñar el gobierno y sus entes administrativos ${ }^{31}$. Este fue un proyecto que representó para los conservadores, "la salvación nacional", el plan global de gobierno incluía tres aspectos: el económico, el jurídico - político y el ideológico ${ }^{32}$

La transformación para la unificación nacional en la Regeneración, fue un proyecto que se realizó "desde arriba" y se excluyó por completo cualquier participación popular; los entes del gobierno asumieron, una actitud autoritaria para evitar cualquier tipo de desorden.

El gobierno regeneracionista a través del concordato firmado con el Vaticano en 1887, le dio a la iglesia católica la función de promulgar la práctica de la religión, y sobre todo la intervención en los asuntos de la moral pública y privada de los ciudadanos y de los problemas del control social.

"Artículo 53. La Iglesia Católica podrá libremente en Colombia administrar sus

\footnotetext{
31JARAMILLO URIBE, Jaime. El proceso de Educación en la República. 1830 - 1886. En: Historia de Colombia. Editorial Planeta. Tomo 2. Bogotá, 1989. P. 233-234

32TIRADO MEJLA, Álvaro. Estado y la Política en el siglo XIX. En: Nueva Historia de Colombia. Editorial Tomo 2. Planeta. Bogotá, 1989. P.
} 
asuntos interiores y ejercer actos de autoridad espiritual y de jurisdicción eclesiástica, sin necesidad de autorización del Poder civil; y como persona juridica, representada en cada Diócesis por el respectivo legítimo Prelado, podrá igualmente ejercer actos civiles, por derecho propio que la presente Constitución le reconoce.

Artículo 54. El ministerio sacerdotal es incompatible con el desempeño de cargos públicos, Podrán, sin embargo, los sacerdotes católicos ser empleados en la instrucción o beneficencia públicas.

Artículo 55.- Los edificios destinados al culto católico, los seminarios conciliares y las casas episcopales y curales no podrán ser gravados con contribuciones ni ocupados para aplicarlos a otros servicios.

Artículo 56. El Gobierno podrá celebrar convenios con la Santa Sede Apostólica a fin de arreglar las cuestiones pendientes, y definir y establecer las relaciones entre la potestad civil y la eclesiástica" ${ }^{\prime 3}$.

Bajo esta filosofia se consolidó el cristianismo práctico como proyecto nacional de dominación, trabajo desarrollado por la iglesia, la cual era vista por los dirigentes políticos hegemónicos conservadores como la única institución capaz de establecer una ligadura ético-religiosa eficaz dentro de un país extenso y desarticulado, con extremas desigualdades sociales, raciales y regionales. Esta institución poseía un aparato burocrático centralizado doctrinario y organizado que gozaba del respeto de las grandes masas; tenia una larga experiencia educativa desarrollada durante tres siglos de dominación colonial, lo que le habia permitido controlar el aparato educativo; era la única con una propuesta y un saber pedagógico que armonizaban a la perfección con los fines sociales asignados a la educación por el nuevo grupo hegemónico, que incluía el tipo de sujeto, hombre y ciudadano que se pretendia formar; y además contaba con recursos materiales y humanos, tanto internos como externos, para colaborar con el proyecto en el plano educativo ${ }^{34}$.

\section{Control de los contenidos curriculares}

El Estado estableció la enseñanza obligatoria de la religión católica y la observancia de las prácticas piadosas, se reservó la facultad de imponer textos de religión, filosofía y moral, de denunciar y hacer excluir a todo docente que pudiera aparecer como sospechosos de creencias morales o religiosas distintas, interferir el contenido literario o científico, se neutralizó la posibilidad de crear un modelo pedagógico local y cesó con la participación de los maestros y los padres en discusiones sobre la educación y la pedagogia, pues era preciso seguir lo establecido ${ }^{35}$.

Dos textos oficiales direccionaron la educación en este periodo; el primero, fue el tratado manual elementos de pedagogía de los hermanos Luis y Martín Restrepo Mejía (1885):

"De acuerdo con el deseo de usted, he examinado personalmente el manuscrito de su obra de Pedagogia, tal como lo tiene preparado para la segunda edición, y lo he

${ }^{33}$ Concordato de 1887 . Titulo IV. De las relaciones entre la Iglesia y el Estado.

${ }^{34}$ SILVA, Renán. La Educación en Colombia 1881-1930. En: Nueva Historia de Colombia. Tomo IV. Editorial Planeta. Bogotá, 1989. P 70.

${ }^{35}$ JARAMILLO URIBE, Jaime. El proceso de Educación en la República. 1830-1886. En: Nueva Historia de Colombia. Editorial Planeta. Tomo II. Bogotá, 1989. P 234. 


\section{PaneraSurcolombiama 16}

detallado perfectamente ortodoxo, tanto en lo que se relaciona más directamente con la doctrina religiosa, como en su parte filosófica.

Por lo demás, la buena intención con que ha sido escrita esta obra, resulta de cada una de sus páginas, así como lo mediato de las observaciones y enseñanzas, para las cuales se ve que usted ha pedido luz no sólo á las autores católicos, sino á todos los que han escrito sobre la materia, cualesquiera que sean sus ideas lo que demuestra que usted ha escrito con conciencia y procurando tener conocimiento perfecto de la materia que trataba. ${ }^{36}$

El segundo texto fue el reglamento de escuelas primarias de la república de Colombia conocido como Plan Zerda expedido en 1893, durante el periodo presidencial de Miguel Antonio Caro, el cual se mantuvo casi intacto hasta 1903. Este documento reglamentó los programas o pénsum de la escuela elemental, la distribución del tiempo, el régimen higiénico, los métodos de enseñanza, el régimen interno de la escuela, las penas y premios, los formatos de registros de libros de la escuela, la asistencia y listado de estudiantes, los deberes religiosos de los directores y alumnos, los periodos escolares, la manera como debian ser entregados los informes de los inspectores locales y la enseñanza de oficios.

"Articulo 2. Los Maestros deben ceñirse á los programas ó pénsum que a continuación se expresan:

ESCUELA ELEMENTAL - AÑO PRIMERO
Lectura. Desde el conocimiento y pronunciación de las letras manuscritas é impresas, hasta leer palabras. Debe combinarse la lectura con la escritura.

Escritura. Ejercicios en pizarra. ${ }^{37 "}$

Todos y cada uno de los aspectos que se desarrollaban dentro de las instituciones y en las oficinas de los encargados de vigilar la instrucción pública estaban reglamentados, de tal manera que no se podian hacer uso de la individualidad, creatividad o autonomía para llevar a cabo funciones, simplemente era necesario conocer los manuales y seguirlos al pie de la letra.

\section{Guía para llevar la asistencia de estudiantes}

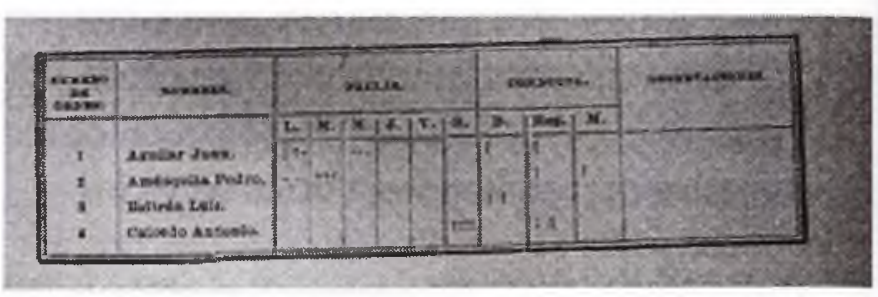

Fuente: Reglamento para les Escuelas Primarias. Capitulo VIII. De los Registros y Libros de Escuela. Diciembre 13 de 1886. Pág. 17

\section{Control de la Instrucción Pública}

El Ministerio de Instrucción Pública fue el encargado de manejar y controlar todo lo relacionado con el tema de la educación, cada departamento tenía como primer agente un Secretario de Instrucción Pública y un Inspector General por cada Provincia.

A las Asambleas les correspondió fomentar con sus propios recursos la instrucción pública primaria y reglamentarla en lo que no fuera objeto de leyes y decretos generales. A los

\footnotetext{
${ }^{36}$ Carta Escrita por el Obispo de Popayán Juan Buenaventura al Señor Martín Restrepo Mejia. Popayán, julio 23 de 1892 . Archivo General de la Nación.

${ }^{37}$ Reglamento para les Escuelas Primarias. Capitulo II. De los Programas o Pénsum. Diciembre 13 de 1886. Pág. 3
} 
Gobernadores les correspondió dirigirla instrucción pública sobre las bases consignadas en las leyes, ordenanzas y decretos del Gobierno, además de ello tenían la potestad para nombrar directores de escuelas (entre ternas presentadas por el Inspector General), crear escuelas rurales y otras de menor importancia ${ }^{38}$.

El departamento del Tolima tenia para ese entonces 4 Inspecciones Generales de Escuela: la Inspección Escolar de la Provincia del Norte, la Inspección Escolar de la Provincia del Centro, la Inspección Escolar de la Provincia de Neiva y la Inspección Escolar de la Provincia del Sur. Estos funcionarios cumplían con la labor de despachar periódicos, hacer llegar la reglamentación, circulares y todo tipo de información de carácter educativo a los colegios, realizar dos visitas a las instituciones pertenecientes a su jurisdicción para verificar su funcionamiento, número de estudiantes matriculados su comportamiento y asistencia; además de ello, eran los directamente encargados de vigilar y controlar el desempeño de los profesores y enviar un informe anual detallado de cada uno de estos asuntos al Secretario de Instrucción Pública del Departamento del Tolima, quien a su vez rendia un informe al Ministerio de Instrucción Pública. De esta manera se creaba un conducto que permitia que el gobierno central estuviera informado de todo lo que sucedía y a la vez tuviese el control directo de la Educación.

"...La asistencia a la escuela es reducida en comparación con las del Norte y el Sur, quizás por la misma pabreza de que he hablado, los resultados en la enseñanza son regulares... ${ }^{39 "}$

| "Como base de la alta inspección escolar encomendada al Gobierno, es deber de las gobernaciones pasar anualmente al Ministro de Instrucción Pública un informe pormenorizado (Decreto número 429) sobre todos los asuntos relacionados con la Instrucción pública en todas sus ramas, in-dicando las medidas que á su juicio deban adoptarse para impulsar la enseñanza" ${ }^{\prime \prime 40}$.

Los funcionarios regionales que desempeñaban este tipo de cargos eran por supuesto simpatizantes y promotores de la política Regeneracionista, pertenecientes al partido conservador; promovian la ideología hegemónica a partir de sus funciones de vigilancia y control. La elaboración de los informes hacia parte importante de sus funciones, la eficacia y eficiencia en este proceso era constantemente evaluada.

"El señor Inspector Escolar de la Provincia últimamente citada, D. Ulpiano C. González, se hizo notable por la falta de cumplimiento de sus deberes. Para demostrarlo sencillamente, basta decir que solo se han recibido en esta Secretaria un informe con fecha 17 de Septiembre de 1893 de los que debió rendir dicho señor en todo el año; que segun noticias fidedignas que se tienen en este despacho, el señor González se dejó ver muy rara vez en las Escuelas y oficinas de su dependencia;

${ }^{38}$ Reglamento para les Escuelas Primarias. Capitulo II. De los Programas o Pénsum: Diciembre 13 de 1886. Pág. 3

Informe del Secretario de Gobierno del Departamento del Tolima. Imprenta del Departamento. Ibagué, 1892. Archivo Histórico de Ibagué. Pág. 21.

${ }^{39}$ Informe Anual. Secretario de instrucción Pública del Departamento del Tolima. 1893. Ibagué Imprenta Departamental. Archivo Histórico de Ibagué.

${ }^{40}$ Informe del Ministro de Instrucción Pública presentado al congreso de Colombia. Sesiones ordinarias de 1894. Imprenta de La Luz. Bogotá 1894. Pág. 8. Biblioteca Nacional. 
que existe en la oficina de Inspección en Honda...ha dejado en su oficina muchos rollos sin abrir con impresos de los correspondientes al año próximo pasado, con reglamentos para las Escuelas primarias y otros folletos que se le enviaron de este despacho para su distribución en la Provincia $41 "$.

El proceso de inserción de nuevos maestros simpatizantes al discurso regeneracionista, fue bastante lento, impidiendo la apertura de nuevas escuelas. La influencia de la iglesia era bastante fuerte en el proceso de designación de los maestros, en este sentido el padre Esteban Rojas Tovar promovió toda una cruzada para traer docentes de órdenes religiosas y así reemplazar con éxito los hostiles al gobierno.

La cuidadosa selección de los empleados para la Instrucción Pública, era una prioridad para el gobierno nacional, pues consideraban que con ello se garantizaba la aplicación de los lineamientos educativos Regeneracionistas. Para ocupar estos cargos no se necesitaba de un conocimiento o dominio de los modelos pedagógicos, sus implicaciones filosóficas o pedagógicas, bastaba con aplicar los reglamentos al pie de la letra y cumplir con el juramento de defender la Constitución.

Los informes elaborados por los servidores de la instrucción pública, dejan ver la preocupación por la manera como se estaban desarrollando los lineamientos educativos, manifestando la inconformidad con las prácticas pedagógicas de los maestros, la poca asistencia de los estudiantes a la escuela, las dificultades económicas para la consecución de recursos en la construcción de estas, pago de maestros y organización administrativa del ramo, mostrando las deficiencias de la administración. Esto deja ver que los funcionarios solo se limitaron a la labor administrativa reducida a la visita de establecimientos para evidenciar procesos y su posterior reporte mediante informes, pero nunca desarrollaron acciones de intervención para ayudar a mejorar las problemáticas de las cuales hacian constante referencia. La elaboración de los informes, se redujo a una labor netamente instrumental que se realizaba por cumplir con un requerimiento del cargo.

\section{Control de la mente}

Establece cual es la finalidad del discurso, persuasivo, de aprendizaje, de adoctrinamiento. El control de la mente abarca mucho más que la sola comprensión del texto o la conversación; incluye el conocimiento personal y social, las experiencias previas, las opiniones personales y las actitudes, ideológicas, normas y valores sociales, entre otros factores que influyen en el modo de pensar de una persona.

Los actores, las acciones y los contextos son tanto contractos mentales como constructos sociales. Las identidades de la gente en cuanto miembros de grupos sociales las forjan, se las atribuyen y las aprehenden los otros, y son por tanto no sólo sociales, sino también mentales. Los contextos son constructos mentales (modelos) porque representan lo que los usuarios del lenguaje construyen como relevante en la situación social. La interacción social en general, y la implicación en el discurso en particular, no presuponen únicamente representaciones individuales tales como modelos (p.e. experiencias, planes); también exigen representaciones que son compartidas por un grupo o una cultura, como

\footnotetext{
${ }^{41}$ Informe Anual. Secretario de instrucción Pública del Departamento del Tolima. 1893. Ibagué Imprenta Departamental. Archivo Histórico de Ibagué

${ }^{42}$ VAN DIJK Teun A. El Análisis Critico del Discurso. En: Anthropos (Barcelona), 186, septiembre-octubre 1999, pp. 23-36.
} 
el conocimiento, las actitudes y las ideologías ${ }^{42}$. Control de la mente a partir de la confluencia entre el Pestalozzianismo y el Tomismo

La configuración del tejido discursivo de este trabajo parte de entender el proceso de formación de una sociedad, a partir del análisis de la educación, ya que este es un elemento fundamental que ayuda a comprender la forma como se consolida la opinión pública de un país y como se mantienen o transforman sus desigualdades y privilegios sociales.

La manera como se oriente un tipo particular de educación influye indiscutiblemente en la cultura, el sistema de pensamiento y de mentalidad de un pueblo, por ello se hace necesario tener en cuenta el significado que nos proporciona su conocimiento histórico para tratar de intuir cono ha sido, pero también cuáles son sus metas probables ${ }^{43}$.

En el caso del periodo en estudio, el discurso hegemónico buscaba el adoctrinamiento de las masas populares; la sociedad no podia existir sin un principio moral unificado, y por ello era solicitada con urgencia la predicación católica del evangelio que permitiría pacificar los ánimos, y establecer un "verdadero orden social", donde cada individuo tuviera un rol específico que cumplir y estuviera siempre dispuesto a obedecer y contribuir al cambio, fortaleciendo a la Nación con su trabajo y entrega.

La transformación para esta unificación nacional, se realizó "desde arriba" y se excluyó por completo la participación popular, el partido hegemónico, asumió en este caso, una actitud autoritaria para evitar cualquier tipo de desorden y desvió de sus intereses.

Durante el periodo presidencial de Miguel Antonio Caro (1892-1898) el modelo pestalozziano, que había sido traido por el partido liberal durante su periodo de su hegemonía, es readaptado buscando cambiar los principios establecidos en las escuelas protestantes y laicas.

El Pestalozzianismo fue proclamado como oficial, convirtiéndose en la base de la pedagogía para la instrucción primaria colombiana que vino a orientar la educación hasta principios de los años treinta del siglo $\mathrm{XX}^{44}$

"Art. 15. El método de enseñanza será el de Pestalozzi perfeccionado ${ }^{45 "}$

Del Pestalozzianismo se obviaron aspectos que se consideraron peligrosos, pues el niño podía quedarse solo, "viendo las cosas". En el terreno de los saberes, el sistema fue asumido como una forma de enseñanza en las escuelas, evadiendo la fundamentación en la producción de la ciencia, basándose solo en desarrollar los sentidos del niño.

A nivel de estrategias político - religiosas, para eliminar el riesgo de formar niños materialistas, se revaloró la tradición cientifica y catequista religiosa, asumiendo la filosofía neoescolástica para la modernización del sistema escolar. Los

${ }^{43}$ SILVA, Renán. La Educación en Colombia 1880-1930. En: Nueva Historia de Colombia. Editorial Planeta. Bogotá, 1989. P. 61.

${ }^{44}$ SAENZ OBREGON, Javier, SALDARRIAGA, Oscar y OSPINA, Armando. Mirar la infancia: pedagogia, moral y modernidad en Colombia, 1903 - 1946. Ediciones Uniandes, Editorial Universidad de Antioquia, Ediciones foro nacional por Colombia y Colciencias. Vol. 1. Santafé de Bogotá, 1997. P. 16-20

${ }^{45}$ Reglamento para les Escuelas Primarias. Capirulo V. De los Métodos. Diciembre 13 de 1886. 
avances metodológicos y organizativos de los saberes experimentales fueron usados pero asegurando los fines sobrenaturales y morales para el individuo, la sociedad y el Estado, es decir fue aceptado el discurso moderno, pero a la vez se validó la lectura de la palabra de Dios ${ }^{46}$.

De esta manera el discurso educativo liberal que antes había sido hegemónico se viene a convertir en este periodo en el contra-hegemónico.

Lineamientos Educativos, hegemónico y Contra- hegemónico. 1886 - 1898

\begin{tabular}{|c|c|}
\hline $\begin{array}{l}\text { Lineamientos } \\
\text { Educativos } \\
\text { Hegemónicos } \\
\text { Educación } \\
\text { Regeneracionista } \\
\text { (conservadora) }\end{array}$ & $\begin{array}{c}\text { Lineamientos } \\
\text { Educativos Anti- } \\
\text { hegemónicos } \\
\text { Educación } \\
\text { Federalista (liberal) }\end{array}$ \\
\hline $\begin{array}{l}\text { Unidad moral } \\
\text { católica en la } \\
\text { vida pública y } \\
\text { privada } \\
\text { Ideal } \\
\text { Educativo: } \\
\text { Cada } \\
\text { individuo } \\
\text { debía tener un } \\
\text { rol específico } \\
\text { que cumplir y } \\
\text { estar siempre } \\
\text { dispuesto a } \\
\text { obedecer y } \\
\text { contribuir al } \\
\text { cambio, } \\
\text { fortaleciendo a } \\
\text { la Nación con } \\
\text { su trabajo y } \\
\text { entrega. } \\
\text { Visión } \\
\text { pedagógica } \\
\text { basada en las } \\
\text { teorías de } \\
\text { Pestalozzi y el } \\
\text { Tomismo } \\
\text { La iglesia } \\
\text { tenia e el } \\
\text { domino directo de la } \\
\text { dire } \\
\text { Educación } \\
\text { Educación } \\
\text { gratuita pero } \\
\text { no obligatoria }\end{array}$ & $\begin{array}{l}\checkmark \text { Laica } \\
\checkmark \text { Ideal } \\
\text { Educativo: } \\
\text { plasmar el } \\
\text { espiritu } \\
\text { civilizador del } \\
\text { liberalismo } \\
\text { Promover el } \\
\text { libre } \\
\text { pensamiento } \\
\checkmark \text { Visión } \\
\text { pedagógica } \\
\text { basada en las } \\
\text { teorías } \\
\text { Pestalozzi de y } \\
\text { Fröebel } \\
\text { Se incluía a los } \\
\text { alumnos, a los } \\
\text { maestros y a } \\
\text { los padres de } \\
\text { familia. } \\
\text { Educación } \\
\text { Obligatoria y } \\
\text { gratuita. }\end{array}$ \\
\hline
\end{tabular}

El discurso conservador tejido alrededor del Pestalozzianismo y el tomismo consolidó un conjunto de creencia, normas y valores socioculturales que determinaron la inclusión del individuo en la sociedad, pero a su vez la exclusión, reflejada en las prácticas de la excomulgación, pérdida del empleo, señalamientos y persecuciones que generaron a su vez resistencias de la clase política contrahegemónica.

Producción y reproducir relaciones de poder desiguales entre hombres y mujeres

Los discurso plasmados en los currículos, dejan ver la diferencia de roles que le otorga la educación regeneracionista a las mujeres y los hombre, por considerarlos diferentes, le otorga a cada uno roles distintos. La mujer debía prepararse para ser buena esposa, ama de casa y al mismo tiempo propulsora de sanas costumbres bajo una sólida formación católica. El hombre por su parte debia formarse en el amor al deber, el afecto a la familia, el patriotismo sincero y la afición por el trabajo bajo los preceptos católicos.

"En ningrin sér debe albergarse la virtud con tanto esmero como en la mujer; la mujer sin la virtud es un sér nulo... La mujer lo que es en la actualidad se lo debe únicamente á la Iglesia; de modo que por una gran deuda de gratitud, por lo menos, la mujer debe ser adicta á la Iglesia incondicional y ciegamente...

...La esencia del hombre, lo que lo distingue del bruto, es el ser racional; la esencia en la mujer, lo que la hizo pasar de la nada social á la existencia civil, es la virtud; sin ella no es un ser racional... ... Pero no basta la virtud en abstracto: debe tener un modelo perfectisimo á quien imitar todos los dias, con suma actividad. El tipo de la mujer en la Nueva Ley es Maria, madre del Verbo Etermo ${ }^{47 " .}$

${ }^{46}$ SAENZ OBREGON, Javier, SALDARRIAGA, Oscar y OSPINA, Armando. Mirar la infancia: pedagogia, moral y modernidad en Colombia, 1903 - 1946. Ediciones Uniandes, Editorial Universidad de Antioquia, Ediciones foro nacional por Colombia y Colciencias. Vol. 1. Santa fé de Bogotá, 1997. P. 83 -85.

${ }^{47}$ Biblioteca Luis Ángel Arango. PBRO. Ordonez, Y. El abismo por el error y el Cielo por María. Imprenta y Libreria de Medardo Rivas. De la Diócesis de Nueva Pamplona. Bogotá, 1896. P. 61-62. 
Producción y reproducción de relaciones de poder desiguales entre los conocimientos prácticos y teóricos con la educación popular

Aunque para Pestalozzi la formación integral consistía en la educación equilibrada entre lo intelectual, lo físico y lo moral, el discurso de los funcionarios regionales mostraba un desdén hacia la formación intelectual, privilegiando la formación física, representada por Pestalozzi en la formación en un arte, pero en el caso de las políticas hegemónica será orientada al aprendizaje de un oficio que le permitiría educar una masa potencial de trabajadores.

"...es la conveniencia de dar á la juventud, lo más pronto posible, conocimientos prácticos para abastecer de elementos para la lucha por la vida, porque las necesidades del pais requieren hoy mayor número de agricultores y artesanos entendidos, que de médicos y abogados,...". ${ }^{48}$

\section{Condicionamiento de la opinión}

Los lineamientos educativos estaban confeccionados de tal manera que las cualidades de sumisión, inteligencia y laboriosidad, debían ser las características propias del buen cristiano, facilitando de esta manera la conservación del poder por parte de la clase política hegemónica. Estos lineamientos no estaban confeccionados partiendo de estudios sobre el estado de la educación del momento o de necesidades directas de la población, sino de la necesidad de controlar y moldear la mentalidad y las prácticas culturales de la población.

Al entregarle el gobierno conservador el control de la educación a la iglesia, le entregó a su vez el control de los medios de comunicación, ya que este ente era el encargado de seleccionar los textos que podian entrar al país, ser publicados y enseñados en las escuelas, de tal manera que la opinión pública fue conducida y regulada por la iglesia con el consentimiento del Estado.

\section{Referencias Bibliográficas}

Biblioteca Luis Ángel Arango. PBRO. Ordoñez, Y. El abismo por el error y el Cielo por Maria. Imprenta y Librería de Medardo Rivas. De la Diócesis de Nueva Pamplona. Bogotá, 1896.

Carta Escrita por el Obispo de Popayán Juan Buenaventura al Señor Martín Restrepo Mejía. Popayán, julio 23 de 1892. Archivo General de la Nación.

Concordato de 1887. Título IV. De las relaciones entre la Iglesia y el Estado.

FAIRCLOUGH, Norman y WODAK, Ruth. Análisis Critico del Discurso. En: El Discurso Como Interacción Social. Teun Van Dijk, Compilador. Editorial Gedisa. España, 2008.

Informe Anual. Secretario de instrucción Pública del Departamento del Tolima. 1893. Ibagué Imprenta Departamental. Archivo Histórico de Ibagué.

Informe del Gobernador del Tolima. Asamblea Departamental en sus Sesiones Ordinarias de 1894. Ibagué. Imprenta del Departamento. 1894. Archivo Histórico De Ibagué

Informe del Ministro de Instrucción Pública presentado al Congreso de Colombia. Sesiones Ordinarias de 1894. Imprenta de La Luz. Bogotá 1894. Biblioteca Nacional.

${ }^{48}$ Informe del Gobernador del Tolima. Asamblea Departamental en sus Sesiones Ordinarias de 1894. Ibagué. Imprenta del Departamento. 1894. Pág. 60 Archivo Histórico De Ibagué 
Informe del Secretario de Gobierno del Departamento del Tolima. Imprenta del Departamento. Ibagué, 1892. Archivo Histórico de Ibagué.

JARAMILLO URIBE, Jaime. El proceso de Educación en la República. 1830 - 1886. En: Historia de Colombia. Editorial Planeta. Tomo 2. Bogotá, 1989.

JARAMILlO URIBE, Jaime. El proceso de Educación en la República. 1830-1886. En: Nueva Historia de Colombia. Editorial Planeta. Tomo II. Bogotá, 1989.

Reglamento para les Escuelas Primarias. Capitulo II. De los Programas o Pénsum. Diciembre 13 de 1886.

SAENZ OBREGON, Javier, SALDARRIAGA, Oscar y OSPINA, Armando. Mirar la infancia: pedagogía, moral y modernidad en Colombia, 1903 - 1946. Ediciones Uniandes, Editorial Universidad de Antioquia, Ediciones foro nacional por Colombia y Colciencias. Vol. 1. Santafé de Bogotá, 1997.
SILVA, Renán. La Educación en Colombia 1881 1930. En: Nueva Historia de Colombia. Tomo IV. Editorial Planeta. Bogotá, 1989.

TIRADO MEJIA, Álvaro. Estado y la Politica en el siglo XIX. En: Nueva Historia de Colombia. Editorial Tomo 2. Planeta. Bogotá, 1989.

VAN DIJK Teun A. Discurso y Poder. Editorial Gedisa. España, 2009.

VAN DIJK Teun A. El Análisis Critico del Discurso. En: Anthropos (Barcelona), 186, septiembre-octubre 1999.

VAN DIJK, Teun A. El Discurso como Interacción en la Sociedad. En: El Discurso Como Interacción Social. Teun Van Dijk, Compilador. Editorial Gedisa. España, 2008. 